\title{
REGULAÇÃO HORMONAL NO METABOLISMO ENERGÉTICO DE NÃO RUMINANTES EM ESTADO DE JEJUM
}

\author{
Jonathan Madson dos Santos Almeida ${ }^{1}$ \\ David Rwbystanne Pereira da Silva ${ }^{1}$ \\ Gabrielle Catarine Castro Pereira ${ }^{1}$ \\ Joelma Vasconcelos Celestino da Silva ${ }^{1}$ \\ Leonardo Augusto Fonseca Pascoal ${ }^{2}$
}

\begin{abstract}
RESUMO
Objetivou-se com esta revisão ressaltar o comportamento hormonal (insulina, glucagon, grelina, leptina, T3, T4, cortisol, adrenalina IGF e GH) atuantes no metabolismo energético de animais não ruminantes sobre o estado de jejum. Os processos metabólicos são regulados pela disponibilidade de substrato, por mecanismos neuroendócrinos. Para entender as vias metabólicas e sua regulação hormonal sobre os diferentes tecidos, faz-se necessário deter-se ao metabolismo especializado sobre os vários órgãos e tecidos que integram o metabolismo energético em todo o organismo do animal. Assim espera-se elucidar o amplo alcance dos hormônios de mobilização de energia e os mecanismos hormonais presente em cada tecido, como também descrever a inter-relação entre a insulina, o glucagon e a adrenalina na coordenação do metabolismo energético do músculo, fígado e tecido adiposo, pois cada tecido tem características metabólicas próprias, de um modo geral, a concentração dos nutrientes no sangue é controlada pelo fígado, que por sua vez, torna-se o órgão central da manutenção da homeostasia dos principais nutrientes. $\mathrm{O}$ aporte energético no organismo durante o período de jejum se dá pela degradação de glicogênio, a proteólise muscular e lipólise que vão desempenhar papéis fisiológicos específicos para que as vias metabólicas tenham características próprias, sendo a liberação dos hormônios regulada por uma hierarquia de sinais neuronais e hormonais. A insulina, o glucagon e outros hormônios relacionados regulam as concentrações de glicose no sangue e atuam sobre o movimento de glicose, aminoácidos e, possivelmente, ácidos graxos de cadeia curta entre o fígado e os tecidos periféricos. O hormônio do crescimento pode alterar a sensibilidade dos tecidos à insulina. Na ausência de insulina, pode ocorrer a proteólise e lipólise, proporcionando substratos para a gliconeogênese e consequentemente, a produção de energia em estado de jejum.
\end{abstract}

Palavras-chave: carboidratos, degradação, lipídeos, proteínas, síntese

\section{HORMONAL REGULATION IN THE ENERGETIC METABOLISM OF NON- RUMINANTS IN STATE OF FASTING}

\begin{abstract}
The objective of this review was to emphasize the hormonal behavior (insulin, glucagon, ghrelin, leptin, T3, T4, cortisol, adrenaline IGF and GH) acting on energy metabolism of nonruminant animals on the fasting state. Metabolic processes are regulated by the availability of substrate, by neuroendocrine mechanisms. To understand the metabolic pathways and their hormonal regulation on the different tissues, it is necessary to stop to the specialized

\footnotetext{
${ }^{1}$ Doutorado Integrado em Zootecnia da Universidade Federal da Paraíba- UFPB. Correspondencia: jonathan_madson@hotmail.com

2 Professor Associado do Departamento de Ciência Animal da Universidade Federal da Paraíba- UFPB. leonardo@cchsa.ufpb.br
} 
metabolism on the various organs and tissues that integrate the energy metabolism in the whole organism of the animal. Thus it is expected to elucidate the broad range of energy mobilization hormones and the hormonal mechanisms present in each tissue, as well as to describe the interrelationship between insulin, glucagon and adrenaline in the coordination of energetic metabolism of muscle, liver and tissue Because each tissue has its own metabolic characteristics, in general, the concentration of nutrients in the blood is controlled by the liver, which in turn becomes the central organ of the maintenance of the homeostasis of the main nutrients. The energy supply in the body during the fasting period is due to the degradation of glycogen, muscular proteolysis and lipolysis that will play specific physiological roles so that the metabolic pathways have their own characteristics, the release of the hormones being regulated by a hierarchy of neuronal signals and hormones. Insulin, glucagon, and other related hormones regulate blood glucose concentrations and act on the movement of glucose, amino acids, and possibly volatile fatty acids between the spinning and peripheral tissues. Growth hormone may alter tissue sensitivity to insulin. In the absence of insulin, proteolysis and lipolysis may occur, providing substrates for gluconeogenesis and, consequently, energy production in the fasting state.

Keywords: carbohydrates, degradation, lipids, proteins, synthesis

\section{REGULACIÓN HORMONAL EN EL METABOLISMO ENERGÉTICO DE NO RUMIANTES EN ESTADO DE AYUNO}

\section{RESUMEN}

El objetivo de esta revision fue resaltar el comportamiento hormonal (insulina, glucagon, grelina, leptina, T3, T4, cortisol, adrenalina, IGF y GH) que actúan sobre el metabolismo energético de animals no rumiantes en estado de ayuno. Los procesos metabólicos están regulados por la disponibilidade de substrato, por mecanismos neuroendocrinos. Para comprender las vías metabólicas y su regulación hormonal en los diferentes tejidos, es necessário detener el metabolismo especializado en los diversos órganos y tejidos que integran el metabolismo energético en todo el cuerpo del animal. Así, se espera dilucidar la amplia gama de hormonas movilizadoras de energia y los mecanismos hormonales presentes en cada tejido, así como describer la interrelación entre insulin, glucagón y adrenalina en la coordinación del metabolismo energético de músculo, hígado y tejido adipose, debido a que cada tejido tiene sus propias características metabólicas, en general, la concentración de nutrientes en la sangre es controlada por el hígado, que a su vez se convierte en el órgano central para mantener la homeostasis de los principals nutrientes. El suministro de energia en el cuerpo durante el período de ayuno se debe a la degradación del glucógeno, la proteólisis muscular y la lipólisis que jugarán roles fisiológicos específicos para que las vías metabólicas tengan sus propias características, con la liberación de hormonas regulada por una jerarquía de señales neuronales y hormonal. La insulina, el glucagón y otras hormonas relacionadas regulan las concentraciones de glucose en sangre y actúan sobre el movimiento de glucose, aminoácidos y posiblemente ácidos grasos de cadena corta entre el hígado e los tejidos periféricos. La hormona del crecimiento puede alterar la sensibilidade de los tejidos a la insulina. En ausencia de insulin, puede ocurrir proteólises y lipólisis, proporcionando substratos para la gluconeogenesis y, en consecuencia, la producción de energia en ayunas.

Palabras clave: carbohidratos, degradación, lipídios, proteínas, síntesis 


\section{INTRODUÇÃO}

Nos últimos anos ocorreram inúmeros avanços na nutrição animal e dentre os recentes estudos têm-se identificado um interesse pela compreensão dos mecanismos envolvidos no metabolismo energético celular em estado de jejum, dado a capacidade de alguns órgãos se modificarem em resposta à mudança fisiológica impostas aos animais.

Os animais não-ruminantes se adaptam a períodos de jejum curtos razoavelmente bem, ao utilizar o estoque de nutrientes como os carboidratos e lipídeos, e o excedente de proteínas. Além disso, mecanismos neuroendócrinos são ativados e contribuem para a redução do gasto de energia e, consequentemente, a preservação da proteína corporal (1) quando há períodos longos sem ingestão de alimentos. No metabolismo energético os hormônios estão envolvidos na regulação da glicose sanguínea de forma direta (com os níveis de insulina e glucagon) e indireta (hormônio de crescimento, adrenalina e tiroxina) mais detalhes sobre o comportamento hormonal serão relatados no decorrer dessa revisão.

O metabolismo energético envolve um processo de transformação de energia em um sistema biológico que compreende etapas de nível celular até o indivíduo como um todo, pelas Leis da termodinâmica e a Lei de Hess, no entanto, o fluxo de energia nos animais torna-se limitado por fatores intrínsecos (capacidade de tecidos - adiposo, muscular, hepático e renal), além do gasto energético do trato gastrintestinal e demais órgãos que participam do fornecimento de nutrientes (2). A capacidade de obtenção de energia a partir da ingestão do alimento define o sucesso produtivo, reprodutivo e outros importantes atributos que podem serem comprometidos pelo estado de jejum, cujo animal esteja submetido.

$\mathrm{O}$ termo jejum pode ser definido como a condição, que devido aos fatores intrínsecos, o animal não ingere alimento por um período de tempo superior ao que normalmente acontece. Em algumas situações o animal tem a oferta de alimentos, mas seu tempo acaba sendo gasto com outras atividades que requerem energia, como aquelas relacionadas a atividades fisiológicas e reprodução, fuga de predadores (3). Nesse cenário, a glicogenólise é temporariamente interrompida, em contrapartida, o organismo animal lança mão de estratégias para o fornecimento de energia como a gliconeogênese e a cetogênese, fundamentais para a sobrevivência durante aquele momento especifico (4).

$\mathrm{O}$ organismo animal permite se ajustar de acordo com a oferta de alimentos. Algumas espécies de animais permitem realizar o jejum por períodos bastantes longos. Nesses animais a homeostase metabólica e as funções dos órgãos permanecem constantes durante o estado de jejum, entretanto, ocorre aumento no metabolismo de lipídeos e elevação nos níveis plasmáticos de ácidos graxos livres, na concentração de ureia, ácido úrico e creatinina na circulação, associados a um aumento no catabolismo de proteínas, quando o jejum persiste por um tempo maior, podendo causar danos irreversíveis ao animal (5).

Durante curtos períodos de jejum, além das modificações já citadas, ocorrem ajustes morfológicos no intestino, como evidenciado em alguns estudos. Karasov et al (6), observaram redução acentuada na massa intestinal, e após a realimentação, há aumento na taxa de proliferação celular. Pucci et al. (7), relataram comprometimento nos processos digestivos e absortivos de nutrientes na fase de realimentação, devido a diminuição na produção enzimática, maior descamação do epitélio intestinal com notável atrofia das vilosidades e hiperplasia das células das criptas e redução do transporte de aminoácidos como glutamina e arginina pela membrana das células.

Aguilar-Nascimento et al. (8), constataram a redução da concentração sérica de insulina e aumento da secreção de glucagon e catecolaminas o que resulta em glicogenólise e lipólise. Este fenômeno favorece maior secreção de hormônio adrenocorticotrófico pela hipófise e aumento da secreção de cortisol pela adrenal. A redução da concentração de insulina e 
elevação dos hormônios adrenérgicos são responsáveis pelas reações catabólicas que fornecem aminoácidos para a corrente sanguínea.

Em relação aos processos de síntese são vários os hormônios que estão envolvidos em seu controle, por exemplo, a insulina estimula a síntese do ácido graxo e do triacilglicerol principalmente por aumentar a permeação da glicose pela membrana celular e secundariamente por aumentar a atividade (provavelmente genética) de várias enzimas lipogênicas. Também aumenta o influxo dos triacilgliceróis do sangue para o tecido adiposo e estimula taxas mais elevadas de deposição de triacilglicerol no tecido adiposo. O tecido adiposo é um tipo especializado de tecido conjuntivo que desempenha papel central no metabolismo energético de todo o animal. Quando o animal possui déficit de energia, os triacilgliceróis são hidrolisados a glicerol e a ácidos graxos, utilizados como combustível metabólico por muitos tecidos (9).

Considerando esses fatos, a compreensão dos mecanismos que dão suporte ao metabolismo energético em condições adversas, assume uma importância considerável do ponto de vista fisiológico, nutricional e bioquímico. Sobre esse contexto, objetivou-se, a partir dessa revisão, abordar aspectos ligados ao metabolismo do estado de jejum em animais nãoruminantes.

\section{CONTROLE ENDÓCRINO E MECANISMO DE AÇÃO HORMONAL}

\section{INSULINA}

A insulina é um hormônio hipoglicêmico que tem como função armazenar o excedente oriundo dos principais nutrientes metabolizáveis para formação do glicogênio, e também participa no direcionamento do acetato e aminoácidos absorvidos para os tecidos periféricos, sendo mais ativa após o estado pós-prandial dos animais.

$\mathrm{O}$ fornecimento energético em estado de jejum é suprido pela glicose gerada no fígado e a mobilização das reservas ocorre pelos centros cerebrais que ativam o hipotálamo. A principal função da insulina é a regulação da homeostase da glicose, em que a modulação da produção de glicose pela insulina envolve a sua sinalização pelos hepatócitos (10) ou a ativação da insulina em locais diferentes do fígado, que por sua vez vão induzir ou inibir a produção de glicose por meio de modeladores neuronais.

$\mathrm{O}$ aumento dos níveis de glicose no sangue inibe o glucagon por meio de um mecanismo de feedback negativo. Durante o estado de jejum a secreção de insulina é reduzida e a de glucagon é aumentada, o que permite estímulo de processos catabólicos e mobilização de glicose e ácidos graxos no metabolismo de carboidratos. Esses efeitos de insulina servem para promover ganho corporal nos animais (11).

$\mathrm{Na}$ ausência de insulina, a captação de glicose diminui nos tecidos e aumenta a mobilização de lipídeos em adipócitos. Na presença de insulina, a captação de glicose aumenta nos tecidos e diminui a mobilização de lipídeos em adipócitos (12). Por exemplo, a glândula mamária do animal lactante é altamente ativa na síntese do triacilglicerol para secreção do leite. Em não ruminantes a glicose é o principal precursor para a síntese do ácido graxo na glândula mamária (9).

Por sua vez, a insulina estimula a glicólise e a glicogênese, e inibe a gliconeogênese e a glicogenólise. Dessa forma, a insulina estimula a absorção e incorporação de aminoácidos em proteínas, inibe a degradação de proteínas, estimula a lipogênese e suprime a lipólise (13).

Os tecidos periféricos, especialmente o músculo esquelético, podem derivar fração significativa de suas necessidades energéticas da oxidação dos corpos cetônicos a $\mathrm{CO}_{2}$ dentro de suas mitocôndrias. Além disso, o músculo cardíaco e o córtex renal utilizam o acetoacetato em lugar da glicose. Apesar da glicose ser o principal combustível no animal bem nutrido, o 
cérebro aumenta a oxidação do acetoacetato, mas não com a exclusão da glicose, durante o jejum (9).

\section{GLUCAGON}

O glucagon é um hormônio hiperglicêmico que estimula o processo de gliconeogênese, sendo considerado anabólico, catabólico e insulínico (11). Os tecidos alvos do glucagon são o fígado, onde ocorre o estímulo a glicogenólise e a gliconeogênese para a manutenção da glicemia; e o tecido adiposo onde o glucagon estimula a lipólise e mobiliza triacilglicerol que resultam em ácidos graxos e glicerol para os tecidos. Esse mecanismo é importante no estado de jejum, pois o glicerol é um substrato com potencial para geração de glicose (14).

É importante ressaltar que o tempo cujo animal é submetido ao jejum vai influenciar possíveis alterações metabólicas em função da secreção de outros hormônios que contribuem para manutenção da homeostase de glicose, e quanto maior o jejum, maior será o número de modificações metabólicas.

Neste sentido, a lipólise é fundamental para que o fígado possa exercer o seu papel de fornecedor de glicose para o organismo. Os níveis dos hormônios adrenérgicos e cortisol incrementam a lipólise, ao disponibilizar ácidos graxos e glicerol. Além disso, o organismo diminui o seu metabolismo basal, devido a menor liberação dos hormônios tireoidianos (T3 e T4) (14).

Dessa forma, o organismo consome menos substratos energéticos, mas o consumo de glicose por alguns tecidos é reduzido em virtude da preferência do cérebro pela glicose, salvo em raras situações em que pode fazer uso de corpos cetônicos. No entanto, uma quantidade maior de corpos cetônicos são gerados no fígado, a partir do acetil-CoA, oriundos da betaoxidação dos ácidos graxos em períodos de jejum prolongado (15). Apesar da dependência do cérebro por glicose, o órgão não pode armazená-la sendo necessário seu suprimento constante.

Diferente da glicose, os ácidos graxos possuem estrutura que impedem sua permeabilidade na barreira hematoencefálica, para disponibilizar energia, portanto, não podem suprir a demanda energética do cérebro (16). Todavia, a glicose só pode ser utilizada pelo tecido hepático após sofrer fosforilação, pela enzima glicoquinase (16) e como a enzima apresenta baixa afinidade pela glicose sua utilização será limitada, então, sobre essas condições, o fígado poderá utilizar outros substratos energéticos para manter o funcionamento adequado do animal. A glicose só será utilizada pelo fígado como nutriente preferencial quando a proporção insulina/glucagon for alta o suficiente para ativar a via glicolítica (16).

Hu et al. (17) avaliaram os efeitos da privação de alimentos em frangos e, os autores encontraram redução de $23 \%$ na concentração de glicose plasmática, que os levam a mobilizar reservas de energia e, por consequência, eleva os níveis de ácido úrico (18), albumina e colesterol total (19). Os efeitos do estado de inanição podem ter suas respostas influenciadas pelo tempo de jejum e a idade do animal, por exemplo, os níveis de ácido úrico no plasma possibilitam que ocorra a oxidação de aminoácidos para tentar manter o nível energético (18). Buyse et al. (20) relataram reduções dos níveis de ácido úrico no plasma após a privação alimentada, provavelmente devido a um efeito poupador sobre a proteína.

\section{LEPTINA}

A leptina é secretada, principalmente, pelo tecido adiposo e reflete a quantidade de gordura depositada no corpo de um indivíduo, apresentando assim, além de outras funções, a de regulação do metabolismo energético dos animais. 
Uma das principais funções da leptina está relacionada a regulação do tecido adiposo corporal, sendo assim este hormônio sinaliza ao cérebro quando os níveis de gordura estão adequados, sendo seu excedente transportado para a corrente sanguínea e, em seguida, para órgãos-alvo (21). Entretanto, diversos fatores influenciam sua síntese, tais como jejum, atividade simpática, exercício físico e alterações no balanço energético (22) que são intermediados por metabólitos presentes na corrente sanguínea que interagem com receptores diretamente no sistema nervoso central e a nível celular.

Quanto ao seu mecanismo de ação, existem cinco tipos de receptores que atuam de forma efetiva ao nível celular, todavia somente o receptor $\mathrm{Ob}-\mathrm{Rb}$ (forma longa) possui domínio intracelular sendo capaz de transmitir o sinal de ligação com a leptina dentro da célula presente em alguns órgãos (pâncreas, rins, medula adrenal, tecido adiposo, tecido mamário, placenta e ovários) e em alguns núcleos hipotalâmicos (23). Quando as reservas energéticas (tecido adiposo) estão elevadas, o centro da saciedade no hipotálamo é ativado, o que provoca redução na ingestão de alimentos. Já durante um período de jejum prolongado, concomitantemente ocorre aumento do apetite e mobilização do tecido adiposo para manutenção do nível glicêmico (24).

A presença de leptina na corrente sanguínea reduz o apetite a partir da inibição da formação de neuropeptídios, como o neuropeptídio $\mathrm{Y}$, e também do aumento da expressão de neuropeptídios anorexígenos, como o hormônio estimulante de $\alpha$-melanócito $(\alpha-\mathrm{MSH})$ e o hormônio liberador de corticotropina (CRH) (25), o que aumenta o gasto energético por ação simpática. A leptina ainda pode ter ação lipolítica, estimulando a lipólise e inibindo a lipogênese, considerando-se um mecanismo de proteção contra a adipotoxicidade provocada pelo excesso de triacilgliceróis no citosol de células que não são adipócitos e, portanto, não estão preparadas para conter grande quantidade de lipídeos em seu interior (26).

Analisando a influência de programas de restrição alimentar com a dosagem de metabólitos envolvidos no metabolismo energético de galinhas reprodutoras, Taherkhani et al. (27) concluíram que os animais que se alimentaram de forma ad libitum apresentaram altas concentrações de leptina, diferentemente daqueles animais que foram alimentados duas ou três vezes ao dia. Os autores ainda relatam a influência negativa da leptina sob os hormônios reprodutivos, principalmente aqueles responsáveis pela luteinização de folículo.

\section{GRELINA}

A grelina é um hormônio produzido e secretado predominantemente pelas células $\mathrm{G}$ do trato gastrintestinal (estômago) e em menores quantidades no sistema nervoso central, rins, placenta e coração, que quando presente na corrente sanguínea aumenta a utilização de carboidratos pelas células, reduz o gasto de gordura, aumenta a motilidade gástrica e secreção ácida, regula o consumo de ração, peso corporal e motilidade gastrintestinal (28).

Sato et al. (29), observaram que a concentração de grelina no plasma sanguíneo aumenta quando em jejum, e diminui no período pós-prandial, e o nível de glicose no sangue pode ser considerado candidato provável na regulação destes níveis, pois a sua administração oral ou intravenosa diminui a concentração de grelina no plasma (30), por isso apontam a alimentação como principal fator de produção deste hormônio.

No que se diz respeito à estimulação do apetite causada pela grelina, esta ocorre pela ativação e estimulação de neuropeptídios hipotalâmicos orexígenos, como o neuropeptídio Y (31). Ela tende a atuar como um sinal da fome dos tecidos periféricos, informando ao cérebro sobre o conteúdo de nutrientes no estômago e ela é considerada um hormônio intestinal com efeitos diretos, possuindo uma variedade de funções biológicas, além de ser o único hormônio estimulante do apetite do intestino até então conhecido (32). 


\section{TRIIODOTIRONINA (T3) E TIROXINA (T4)}

Os hormônios tireoidianos desempenham importante papel no metabolismo energético, pela regulação do funcionamento do tecido adiposo, estando relacionados principalmente com mudanças de peso corporal (33). A glândula tireoide faz parte do eixo hipotálamo-hipófisetireoide e produz, principalmente, os hormônios tireoidianos triiodotironina (T3) e tiroxina (T4). Porém, também produz outras iodotironinas, como T3 reverso e 3,5-diiodo-l-tironina. A secreção desses hormônios é regulada pelo mecanismo clássico de feedback negativo, no qual, o hormônio liberador da tireoide (TRH), produzido predominantemente por neurônios do núcleo para ventricular no hipotálamo, estimula a liberação de hormônio estimulador da tireoide (TSH) na hipófise e este, por sua vez, estimula a síntese e liberação do T3, T4 e demais (34).

Alguns estudos já demonstraram que os níveis dos hormônios tireoidianos diminuem significativamente durante um período de restrição alimentar em peixes (35), porém esses níveis são restabelecidos em diferentes taxas durante a realimentação. É relatado também, que esses hormônios estão associados a um mecanismo de sobrevivência, por promoverem a redução de mobilização metabólica das reservas de energia, como também a sua diminuição em longos períodos de jejum alimentar (36). Takahashi (37) ao submeterem juvenis de pacu a pequenos ciclos de privação alimentar, observaram redução dos níveis de triiodotironina (T3) circulantes, demonstrando a influência da alimentação na regulação desses hormônios.

\section{CORTISOL}

O cortisol é um hormônio glicocorticoide sintetizado pelo córtex da suprarrenal envolvido principalmente na resposta ao estresse, aumento da pressão arterial e da glicose sanguínea (38). Além disso, segundo esses autores, o cortisol é o principal hormônio do córtex da suprarrenal que interage profundamente no metabolismo da glicose, das proteínas e dos ácidos graxos livres.

O hormônio cortisol, assim como outros hormônios esteroides, utilizam na sua síntese o pregnenolona (39). A síntese desses hormônios inicia-se dentro da mitocôndria pela clivagem enzimática da cadeia lateral da molécula de esteroide dando origem ao composto esteroide C21, conhecido como pregnenolona. O ponto crítico na síntese desses hormônios adrenais é a etapa de hidroxilação no C-21, a qual é catalisada pela enzima hidroxilase C-21 (40).

A atividade do cortisol é predominantemente catabólica, principalmente em situações de exercício físico e no estado de jejum, pois o mesmo induz a proteólise e a lipólise devido a ativação da via da gliconeogênese hepática e consequentemente a elevação da glicemia (41). O cortisol tem como ação principal facilitar a conversão e a manutenção das proteínas em glicogênio, maximizando a degradação e inibindo a síntese proteica, e assim mobilizar proteínas musculares e disponibilizar aminoácidos para gliconeogênese (42). Ademais, a alanina e outros aminoácidos que não participam da gliconeogênese, tem seus níveis plasmáticos aumentados (41).

O lactato e os aminoácidos são transportados do tecido adiposo e musculoesquelético, fígado e rins para dar início ao processo da gliconeogênese (43). Nessa via, o cortisol tem como função estimular a síntese da enzima fosfoenolpiruvato carboxiquinase (39). De acordo com Rojas e Schwartz (44), o fígado é o principal órgão responsável pela produção da glicose em jejum prolongado.

Bartness e Song (42), relatam que nos períodos de jejum os níveis de cortisol aumentam, e o mesmo tem função de criar reservas de aminoácidos e na fase final da 
hipoglicemia, ele se torna responsável pela diminuição do consumo e aumento na produção de glicose. O cortisol ainda estimula a liberação de glucagon e quando em concentração elevada, tem ação antagonista com a insulina, aumentando os níveis plasmáticos de glicose pelas vias intracelulares (41).

O cortisol juntamente com a adrenalina, o hormônio de crescimento e os peptídeos lipolíticos tem a função de potencializar a lipólise complementando o metabolismo proteico em situações de jejum, porém, o cortisol no metabolismo lipídico também aumenta o apetite e a ingestão calórica (42). Quando em estado de jejum, em consequência da lipólise do tecido adiposo, ocorre a libertação de ácidos graxos, que são convertidos em corpos cetônicos no fígado pelo processo de $\beta$-oxidação e da cetogênese (45). Esse mesmo autor comenta que a $\beta$ oxidação mitocondrial fornece energia para os hepatócitos e gera corpos cetônicos, como o $\beta$ hidroxibutirato, acetoacetato e acetona, que após serem exportados para a corrente sanguínea irão fornecer combustíveis metabólicos para os tecidos extra-hepáticos.

O cortisol ainda estimula a lipogênese e a diferenciação de adipócitos em zonas corporais especificas, como abdômen, tronco e face; de maneira que seja considerado hiperglicemiante, lipolítico e cetogênico, além de aumentar a resistência à ação da insulina, quando está em níveis elevados no plasma (42).

Alguns trabalhos realizados com peixes em jejum mostram resultados contraditórios em relação aos níveis de cortisol, porém os maiores níveis basais desse hormônio indicam possível efeito do mesmo sobre os processos catabólicos desencadeados para produção de energia durante o estado de jejum (46).

\section{ADRENALINA}

A glândula adrenal sintetiza e secreta diferentes hormônios, dentre eles, o principal produto de secreção das células cromafins, com cerca de $85 \%$ é a adrenalina (47). A adrenalina tem múltiplos papeis no metabolismo intermediário durante o estado de jejum.

Em condições de privação alimentar, ocorre aumento das concentrações plasmáticas das catecolaminas, principalmente da adrenalina em até 50 vezes, cuja função é ativar as vias metabólicas da glicogenólise, a gliconeogênese e a lipólise (48). Essas vias são importantes para o fornecimento de glicose para o sistema nervoso central, o qual utiliza a mesma como fonte exclusiva de energia, para maior disponibilidade de ácidos graxos e glicerol plasmático, podendo respectivamente os mesmos serem substratos alternativos de energia fonte de carbonos para a gliconeogênese. As respostas da via glicogenolítica são desencadeadas diretamente pela ativação de adrenorreceptores $\beta_{2}$ e do aumento das concentrações de AMPc, dessa forma, a adrenalina por meio de mecanismos de fosforilação, ativa a enzima glicogênio fosforilase e inibe a glicogênio sintase para que ocorra a degradação do glicogênio e o aumento da produção hepática de glicose (47). As reservas de glicogênio hepático têm um prazo curto para esgotar-se e assim há um aumento da atividade da via gliconeogênica.

Nesse momento, a resposta adaptativa ao jejum é a mobilização de aminoácidos do tecido muscular para suprir as necessidades de energia do organismo, na qual inicialmente ocorre aumento na liberação de aminoácidos dos músculos esqueléticos, resultante da diminuição da síntese proteica e do aumento excessivo na degradação das proteínas (48). Segundo o mesmo autor, devido a esse metabolismo de proteínas musculares, há uma redução dos níveis circulantes de insulina e aumento dos glicocorticoides. É importante citar que nesse tecido devido à ausência da glicose 6 fosfatase, a glicose 6-fosfato produzida na glicogenólise é metabolizada pela glicólise em lactato, a qual será liberada e transformado em glicose pela gliconeogênese (15).

De acordo com Malheiros (15) o aumento da atividade da via glicogenolítica e a produção de lactato estimulados pela adrenalina nos músculos esqueléticos, são extremamente 
importantes na resposta contra regulatória ao jejum, além disso, a proteólise muscular, resultado da diminuição de insulina e do aumento do cortisol é uma resposta metabólica eficaz para a liberação de substratos para o fígado realizar a gliconeogênese.

A adrenalina pode também atuar no tecido adiposo, em que a mesma se acopla em pelo menos quatro subtipos de adrenorreceptores e assim estimula a enzima lipase hormônio sensível, a qual irá degradar os triglicerídeos, o que aumentará a mobilização de ácidos graxos livres (AGL) e glicerol no plasma (43). A partir de então, os AGL podem ser oxidados pelo musculo esquelético e coração ou serem utilizados como precursores para a cetogênese no fígado e o glicerol poderá ser usado para a gliconeogênese.

No estudo realizado por Pinheiros (49) foi analisado o efeito do jejum sobre a capacidade neoglicogenética hepática de duas espécies de morcegos frutívoros e a atividade das principais enzimas relacionadas à esta via metabólica. Além disso, foram avaliados os níveis circulantes de glicose, AG, lactato e triacilgliceróis, além de concentrações de glicogênio, proteína e lipídeos musculares e hepáticos. Observou-se que somente após jejum de 48 horas, a via da gliconeogênese teve sua atividade aumentada e que não houve alterações nas enzimas desta via no jejum. Com relação as concentrações de glicogênio hepático e muscular, houve redução drástica a partir de 24 e 72 horas, respectivamente após a restrição alimentar.

\section{HORMÔNIO DO CRESCIMENTO (GH) e FATOR SEMELHANTE À INSULINA (IGF)}

O hormônio do crescimento $(\mathrm{GH})$ ou somatotropina é sintetizado e secretado pelos somatotrofos, sendo o mais abundante hormônio da hipófise anterior (50). Para Rotunno e Zania (51) o GH é secretado em pulsos e essa liberação é regulada pelo hormônio liberador do hormônio do crescimento (GHRH) e pelo fator inibidor somatostatina (SS). Na corrente sanguínea o GH é ligado a proteínas especificas de alta afinidade (GHBP) constituída de um receptor de $\mathrm{GH}$, e a outra de baixa afinidade (50). O GH age no fígado e dá origem as somatomedinas, as quais estimulam o crescimento dos tecidos e podem também ser secretadas por outros tecidos.

Dentre os fatores de crescimento, os principais circulantes são os fatores de crescimento insulínico ou IGFs (Insulin-like growth factors), que tem uma semelhança estrutural com a pró-insulina e atua acentuadamente sobre o metabolismo intermediário, a proliferação, o crescimento e a diferenciação celular (52).

O GH tem atividade anabólica, já que o mesmo tem a função de estimular o crescimento tecidual e uma metabólica, pois ele consegue alterar o fluxo, a oxidação e o metabolismo de quase todos nutrientes na corrente sanguínea. Essas ações são complexas e podem ser divididas em ações direta, quando mediadas por sinalizações intracelulares as quais são desencadeadas quando o GH se liga ao receptor na membrana plasmática; e indiretas quando são sinalizadas pela síntese de IGF e de suas proteínas transportadoras plasmáticas (48).

No metabolismo lipolítico e glicolítico, o GH tem efeito antagônico ao da insulina, o mesmo tem efeito de hormônio "diabetogênico", pois ele aumenta as concentrações de glicose circulante e, dessa forma, estimula a liberação de insulina para manter a glicemia em níveis adequados (53). Em situações de jejum prolongado ou não, o GH promove a diminuição da quebra da glicose e captação pelos tecidos, além de aumentar a lipólise e a oxidação de ácidos graxos no tecido adiposo, na musculatura esquelética e cardíaca e ainda estimula a produção hepática de glicose pela glicogenólise (53). Em situação de jejum ou exercício, ocorre balanço energético negativo e isso reduz as concentrações de IGF, e o contrário também é verdadeiro, pois com uma superalimentação, as concentrações de IGF aumentam significativamente (54). 
A restrição alimentar acompanha modificações no metabolismo animal pois muda os níveis plasmáticos de vários hormônios que modulam o metabolismo energético e o crescimento, e inclui-se entre eles, o GH e os IGF's. Essas modificações induzem mudanças na atividade de enzimas dos tecidos hepáticos e adiposo, fazendo com que haja disponibilidade de energia para os processos vitais e de crescimento no organismo (55). De acordo com Li et al. (56) a restrição precoce de alimentos antecipa a conversão das miofibrilas musculares de contração lenta para a rápida, o que retarda o crescimento muscular a longo prazo.

Em um estudo realizado por Gasparino et al. (57) foi avaliada a expressão de mRNA IGF-I e GHR no fígado de codornas de corte submetidas a estresse térmico com a suplementação de metionina. Foi verificado que o estresse térmico de $38^{\circ} \mathrm{C}$ por 24 horas pode afetar negativamente a expressão desses genes relacionados ao crescimento, sendo que a suplementação com o aminoácido em estudo pode manter os níveis de mRNA IGF-I e GHR adequados para o metabolismo animal.

\section{CONSIDERAÇÕES FINAIS}

As alterações metabólicas envolvidas no processo de jejum causam disfunções fisiológicas importantes que comprometem a manutenção da funcionalidade celular e, consequentemente, a homeostase corpórea. Os hormônios têm a função de controle e regulação de todas as atividades fisiológicas e em longos períodos de jejum tem sua síntese e excreção alterados. São escassos os trabalhos que correlacionam o estado de jejum em não ruminantes e a atividade hormonal, sendo necessárias pesquisas que visem elucidar alguns questionamentos.

\section{REFERÊNCIAS}

1. Barendregt K, Soeters P, Allison S, Sobotka L. Basics in clinical nutrition: simple and stress starvation. Eur J Clin Nutr Metabol. 2008;3:e267-71.

2. Speakman JR, Król E. Limits to sustained energy in take IX: a review of hypotheses. J Comp Physiol. 2005;175:375-94.

3. McCue MD. Starvation physiology: reviewing the different strategies animals use to survive a common challenge. Comp Biochem Physiol A Mol Integr Physiol. 2010;156:118.

4. Campbell I. Starvation, exercise, injury and obesity. Anaesth Crit Care Pain Med. 2007; 8:299-303.

5. Wang T, Hung CCY, Randall DJ. The comparative physiology of food deprivation: from feast to famine. Ann Rev Physiol. 2006;68:223-51.

6. Karasov WH, Pinshow B, Stark JM, Afik D. Anatomical and histological changes in the alimentary tract of migrating blackcaps (Sylvia atricapilla): a comparison among fed, fasted, food-restricted, and refed birds. Physiol Biochem Zool. 2004;77:149-60.

7. Pucci ND, Fontes B, Poggetti RS. Avaliação de um esquema de realimentação utilizado após 43 dias de jejum voluntário. Rev Nutr. 2008;21:503-12.

Almeida JMS, Silva DRP, Pereira GCP, Silva JVC, Pascoal LAF. Regulação hormonal no metabolismo energético de não ruminantes em estado de jejum. Vet. e Zootec. 2021;28: 001-014. 
8. Aguilar-Nascimento JE, Perrone F, Prado LIA. Jejum pré-operatório de 8 horas ou de 2 horas: o que revela a evidência? Rev Col Bras Cir. 2009;36:350-2.

9. Dukes HH, Reece WO. Fisiologia dos animais domésticos. 12a ed. Rio de Janeiro: Guanabara Koogan; 2006.

10. Thorens B, Mueckler M. Glucose transporters in the 21st Century. Am J Physiol Endocrinol Metab. 2010;298:E141-5.

11. Mohammed MQ, Mutassim MA. Role of insulin and other related hormones in energy metabolism - a review. Cogent Food Agric. 2016;2.

12. Frayn KN. Metabolic regulation: a human perspective. 3rd ed. Oxford: University of Oxford; 2009.

13. Bassett J. Controle dietético e gastro-intestinal de hormônios que regulam o metabolismo de carboidratos em ruminantes. Dig Metabol Rumin. 1975;383-8.

14. Coelho RG. Integrações do metabolismo em exercício, jejum e no estado alimentado. Cienc Atual. 2016;8:2-9.

15. Malheiros SVP. Integração metabólica nos períodos pós-prandial e de jejum: um resumo. Rev Ens Bioquim. 2006;4:16-22.

16. Voet D, Voet JG. Fundamentos de bioquímica. Porto Alegre: Artmed; 2002.

17. Hu X, Lei L, Zhigang S. Effects of feed deprivation on the AMPK signaling pathway in skeletal muscle of broiler chickens original research article. Comp Biochem Physiol A Mol Integr Physiol. 2016;191:146-54.

18. Song Z, Liu L, Yue Y, Jiao H, Lin H, Sheikhamad A, et al. Fasting alters protein expression of AMP-activated protein kinase in the hypothalamus of broiler chicks (Gallus gallus domesticus). Gen Comp Endocrinol. 2012;178:546-55.

19. Savendahl L, Underwood LE. Fasting increases serum total cholesterol, LDL cholesterol and apolipoprotein B in healthy, nonobese humans. J Nutr. 1999;129:2005-8.

20. Buyse J, Janssens K, Geyten SV, As PV, Decuypere E, Darras VM. Pre-and postprandial changes in plasma hormone and metabolite levels and hepatic deiodinase activities in meal-fed broiler chickens. Br J Nutr. 2002;88:641-53.

21. Negrão AB, Licinio J. Leptina: o diálogo entre adipócitos e neurônios. Arq Bras Endocrinol Metabol. 2000;44:205-14.

22. Tavernier G, Jimenez M, Giacobino JP, Hulo N, Lafontan M, Muzzin P, et al. Norepinephrine induces lipolysis in $\beta 1 / \beta 2 / \beta 3$-adrenoceptor knockout mice. Mol Pharmacol. 2005;68:793-9.

23. Karlsson C, Lindell K, Svensson E, Bergh C, Lind P, Billig H. Expression of functional leptin receptors in the human ovary. J Clin Endocrinol Metab. 1997;82:4144-8. 
24. Salman AKD, Costa RB. Ação hormonal da leptina em ruminantes. Porto Velho: Embrapa Rondônia; 2006.

25. Friedmann JM, Halaas JL. Leptin and the regulation of body weight in mammals. Nature. 1998;395:763-70.

26. Donato Junior J, Pedrosa RG, Tirapegui J. Aspectos atuais da regulação do peso corporal: ação da leptina no desequilíbrio energético. Rev Bras Cienc Farm. 2004;40:273-87.

27. Taherkhani R, Zaghari M, Shivazad M, Shahneh AZ. A twice-a-day feeding regimen optimizes performance in broiler breeder hens. Poult Sci. 2010;89:1692-702.

28. Wierup N, Bjorquivist M, Westrom B, Pierzynowski S, Sundler F, Sjolund K. Ghrelin and motilin are cosecreted from a prominent endocrine cell population in the small intestine. J Clin Endocrinol Metab. 2007;92:3573-81.

29. Sato T, Nakamura Y, Shiimura Y, Ohgusu H, Kangawa K, Kojima M. Structure, regulation and function of ghrelin. J Biochem. 2012;151:119-28.

30. Shiiya T, Nakazatu M, Mizuta M, Date H, Mondal MS, Tanaka M, et al. Levels in lean and obese humans and the effect of glucoseon ghrelin secretion. J Clin Endocrinol Metab. 2002;87:240-4.

31. Cowley MA, Smith RG, Diano S, Tschop M, Pronchuk N, Grove KL, et al. The distribution and mechanism of action ofghrelin in the CNS demonstrates a novel hypothalamic circuitregulating energy homeostasis. Neuron. 2003;37:649-61.

32. Kaiya H, Miyazato M, Kangawa K, Peter RE. Ghrelin: a multifunctional hormone in nonmammalian vertebrates. Comp Biochem Physiol A Mol Integr Physiol. 2008;149:109-28.

33. Pinkney JH, Goodrick SJ, Katz J, Johnson AB, Lightman SL, Cop ACK. Leptin and the pituitary - thyroid axis: a comparative study in lean, obese, hypothyroid and hyperthyroid subjects. Clin Endocrinol. 1998;49:583-8.

34. Feldt-Rasmussen U. Thyroid and leptin. Thyroid. 2007;17:413-9.

35. Farbridge KJ, Leatherland JF. Plasma growth hormone levels in fed and fasted rainbow trout (Oncorhynchus mykiss) are decreased following handling stress. Fish Physiol Biochem. 1992;10:67-73.

36. Blanton ML, Specker JL. The Hypothalamic-pituitary-thyroid (HPT) axis in fish and its role in fish development and reproduction. Crit Rev Toxicol. 2007;37:97-115.

37. Takahashi LS, Biller JD, Criscuolo-urbinati E, Urbinati EC. Feeding strategy with alternate fasting and refeeding: effects on farmed pacu production. J Anim Physiol Anim Nutr. 2011;95:259-66.

38. Mcardle W, Katch FI, Katch VL. Fundamentos de fisiologia do exercício. 3a ed. Rio de Janeiro: Guanabara Koogan; 2008.

Almeida JMS, Silva DRP, Pereira GCP, Silva JVC, Pascoal LAF. Regulação hormonal no metabolismo energético de não ruminantes em estado de jejum. Vet. e Zootec. 2021;28: 001-014. 
39. Cunha DF, Arreguy Baptista RIA, Barbosa CN. Cortisol como indicador do estresse na espécie suína. Med Vet (Recife). 2012;6:18-25.

40. Cunninghan JG. Tratado de fisiologia veterinária. Rio de Janeiro: Guanabara Koogan; 2008.

41. França SC, Neto TLB, Agresta MC, Lotufo RFM, Kater CE. Resposta divergente da testosterona e do cortisol séricos em atletas masculinos após uma corrida de maratona. Arq Bras Endocrinol Metabol. 2006;50:1082-7.

42. Bartness TJ, Song CK. Thematic review series: adipocyte biology. Sympathetic and sensory innervation of white adipose tissue. J Lipid Res. 2007;48:1655-72.

43. Lafontan M. Advance in adipose tissue metabolism. Int J Obes. 2008;32:S39-51.

44. Rojas JM, Schwartz MW. Control of hepatic glucose metabolism by islet and brain. Diabetes Obes Metab. 2014;16:33-40.

45. Rui L. Energy metabolism in the liver. Compr Physiol. 2014;4:177-97.

46. Barcellos LJG, Marqueze A, Trapp M, Quevedo RM, Ferreira D. The effects of fasting on cortisol, blood glucose and liver and muscle glycogen in adult jundia Rhamdia quelen. Aquaculture. 2010;300:231-6.

47. Pauli JR. Novos mecanismos moleculares de ação do exercício físico sobre o tecido hepático para o controle glicêmico. Arq Bras Endocrinol Metabol. 2012. (10o Congresso Paulista de Diabetes e Metabolismo).

48. Cruuzat VF, Donato Junior J, Tirapegui J, Schneider CD. Growth hormone and physical exercise: current considerations. Rev Bras Cienc Farm. 2008;44:549-62.

49. Pinheiro EC. Metabolismo intermediário de morcegos frugívoros [tese]. Ribeirão Preto: Universidade de São Paulo; 1995.

50. Ascoli M, Segaloff DL. Adenohypophyseal hormones and their hypothalamic releasing factors. In: Hardman JG, Limbird LE, editors. Goodman \& Gilman's the pharmacological basis therapeutics. 9th ed. New York: McGraw-Hill; 1996. p.1363-82.

51. Rotunno LRA, Zaia CTBV. Growth hormone $(\mathrm{GH})$ and insulin-like growth factors (IGFs). Their functions on the growth and metabolismo. Rev Bras Med. 2001;58:677-84.

52. Martinelli Júnior CE, Custódio RJ, Oliveira MHA. Fisiologia do Eixo GH-Sistema IGF. Arq Bras Endocrinol Metabol. 2008;53:717-25.

53. Ghanaat F, Tayek JA. Growth hormone administration increases glucose production by preventing the expected decrease in glycogenolysis seen with fasting in healthy volunteers. Metabolism. 2005;54:604-9. 
54. Kats E, Deleon DD, Zhao H, Jawad AF. Free and total insulin-like fator (IGF-I) levels decline durant fasting: relationships with insulin and IGF-I bilding protein-1. J Clin Endocrinol Metab. 2003;87:2978-83.

55. Zhan XA, Wang M, Ren H, Zhao RQ, Li JX, Tan ZL. Effect of early feed restriction on metabolic programming and compensatory growth in broiler chickens. Poult Sci. 2007;86:654-60.

56. Li Y, Yuan L, Yang X, Ni Y. Effect of early feed restriction on myofibre types and expression of growth-related genes in the gastrocnemius muscle of crossbred broiler chickens. Br J Nutr. 2007;98:310-9.

57. Gasparino E, Vesco APD, Grieser DO, Zancanella V, Nascimento CS, Guimarães SEF. Efeitos do estresse térmico agudo e da suplementação de metionina sobre a expressão de mRNA IGF-I GHR no fígado de codornas de corte. In: 10o Simpósio Brasileiro de Melhoramento Animal; 2013; Uberaba. Uberaba: SBMA; 2013.

Recebido em: 12/10/2020

Aceito em: 28/02/2021 